\title{
Nadir karşılaşılan sık karıştırılan bir tümör: Lenfanjiyoma Sir- kumskriptum (Yüzeyel Lenfatik Malformasyon)
}

\author{
A Rarely Encountered, Frequently Misleading Tumor: Lymphangioma Circumscriptum \\ (Superficial Lymphatic Malformation)
}

\section{Alper URAL ${ }^{1}$, Fatma BILLGEN ${ }^{1}$, Abdülkadir Yasir BAHAR ${ }^{2}$, Mehmet BEKERECIOOĞLU ${ }^{3}$}

${ }^{1}$ Dr. Öğr. Üy. Kahramanmaraş Sütçü İmam Üniversitesi Tıp Fakültesi, Plastik Rekonstrüktif ve Estetik Cerrahi Ana Bilim Dalı, KAHRAMANMARAS

${ }^{2}$ Dr. Öğr. Üy. Kahramanmaraş Sütçü İmam Üniversitesi Tip Fakültesi, Tibbi Patoloji Ana Bilim Dalı, KAHRAMANMARAŞ

${ }^{3}$ Prof. Dr. Kahramanmaraş Sütçü İmam Üniversitesi Tip Fakültesi, Plastik Rekonstrüktif ve Estetik Cerrahi Ana Bilim Dall, KAHRAMANMARAŞ

\section{Öz}

Lenfanjiyoma Sirkumskriptum yüzeyel lokalize bir lenfanjiom varyantıdır. Karakteristik klinik prezentasyonu kümelenmiş vezikül yada papüloveziküller şeklindedir. Çoğu lenfanjiyomlar konjenital gelişmesine rağmen erişkin yaşlarda da görülebilmektedir.Bu yazıda kliniğimizde tedavi ettiğimiz sağ aksiller bölgede ve meme başında nüks etmiş bir lenfanjioma sirkumskriptum olgusu sunulmuştur. Lenfanjiyoma sirkumskriptum hastalığının tekrarlama ve ikincil malignite gelişebilmesi nedeniyle doğru tanı ve tedavi çok önemlidir. Çeşitli tedavi seçenekleri olmasına karşın özellikle rekürren vakalar için cerrahi eksizyon altın standart olup hastaların takibe alınması elzemdir

Anahtar Kelimeler: Lenfanjiyoma sirkumskriptum, lenfatik malformasyon, vasküler tümörler

\section{Abstract}

Lymphangioma Circumscriptum is a superficially localized variant of lymphangioma. The characteristic clinical presentation is a grouping of vesicles or papulovesicles. Though most lymphangiomas develop congenitally, the lymphangioma circumscriptum subtype is known to present also in adults. We report a case of recurrent lymphangioma circumscriptum on the right axillary and periareolar area treated in our clinics. Accurate diagnosis and treatment is crucial in cases of lymphangioma circumscriptive because of the possibility of recurrence of this disease and the possibility of developing malignancy secondarily. Besides the various treatment modalities, surgical excision is the gold standard especially for recurrent cases and the patients need to be followed-up.

Keywords: lymphangioma circumscriptum,lymphatic malformation,vascular tumors

\section{GİRIS}

Lenfanjiyomalar lenf bulunduran vasküler yapıların genişlemesi sonucu oluşan lenfatik sistemin tümör benzeri oluşumlarıdır. Lenfanjiyoma sirkumskriptum, yüzeysel lokalize bir lenfanjiyom varyantıdır. Karakteristik kliniği proksimal ekstremite veya ekstremite ve kuşak bölgelerinde kurbağa yumurtaları gibi çoklu vezikül veya papuloveziküller şeklindedir. Çoğu lenfanjiyoma konjenital gelişmesine rağmen, lenfanjiyoma sirkumskriptum alt tipi \% 90'ı 2 yaş civarı olmak üzere en sık çocuklarda gözlenir (1). Lenfanjiyomların en sık tipi olan kutanöz lenfanjiyoma sirkumskriptum artık literatürde yüzeyel lenfatik malformasyon olarak tanımlanmaktadır (2). Konjenital olanları esasen neoplastik değlişimle değil de lenfatik sistemin hamartomatöz bir malformasyonu sonucu geliştiği için daha ziyade lenfatik malformasyon olarak isimlendirilir. Klinikte ayırıcı tanıları olan lenfanjiyektazi, telenjiektazi hemanjiyom, anjiyokeratom, lenfanjiosarkom, verruka, molluscum kontagiosum, verrukalar, melanomlar ve epidermal nevus ile sıkça karıştırılabilmektedir $(3,4) . \mathrm{Bu}$ olguda diğer benign lezyonlar ile karışabilen nadir rastlanan bir hastalık olan

$\begin{array}{ll}\text { İletişim: } & \begin{array}{l}\text { Dr. Alper Ural, KSÜ Tip Fakültesi, Plastik, Rekonstrüktif } \\ \text { ve Estetik Cerrahi AD, Kahramanmaraş }\end{array} \\ \text { DOI: } & \mathbf{1 0 . 1 7 5 1 7 / k s u t f d . 4 5 5 8 1 8}\end{array}$

lenfanjiyoma sirkumskriptum olgusunu ve yönetimini sunmayı hedefledik.

\section{OLGU SUNUMU}

12 yaşında erkek çocuk hasta sağ meme areola cilt sınırında ve aksiller bölgesinde değişken boyutlardaki ve çok sayıdaki veziküler görünümlü lezyonları ile kliniğimize ailesi tarafından getirildi (Resim 1). Hastanın 6 yıl önce sağ toraks anterolateral duvarında benzer görünümlü lezyonlar nedeni ile ameliyat edilmiş ve histopatoloji raporu lenfanjiyoma sirkumskriptum olarak gelmiş. Önceki ameliyatına bağlı lezyonların eksizyonu sonrası oluşan skarları gözlenebilmekteydi. Hastanın ek hastalığı veya kullandığı devamlı bir ilacı yoktu. Hastanın sağ toraks ön ve yan duvarı, aksilla ve areola çevresindeki açık pembe renkli çok sayıda papüler ve nodüler yapılarda bazıları lobüle yapılı ve bitişik olan sert kıvamlı lezyonları mevcuttu. Toplamda 25 adet lezyon 19 spesmen şeklinde her lezyon $1 \mathrm{~mm}$ güvenlik sınırı ile ve tabanındaki adipoz dokuya kadar olmak üzere total olarak rezeke edildi. Ameliyat sonrasinda herhangi bir komplikasyon ile karşılaşılmadı. Klinik olarak muayenesinde çoğu

$\begin{array}{ll}\text { Tel } & : 05396679506 \\ \text { E-Posta } \quad: \text { alperural@ksu.edu.tr } \\ \text { Geliş Tarihi : } & 31.08 .2018 \\ \text { Kabul Tarihi : } & 16.01 .2019\end{array}$


lezyonun görüntüsü seroz veya serohemorajik içerikli veziküller içeren düzensiz plaklar veya veziküller şeklinde idi. Histopatolojik değerlendirme sonucunda lenfanjioma circumscriptum ile uyumlu geldi. Hematoksilen-eozin boyamada $4 \mathrm{x}$ büyütmede alınan görüntülerde retiküler ve papiller dermiste ince duvarlı lenfatik damarlar net olarak seçilmektedir (Resim 2).

Resim 1. Aksiller bölge ve meme lateralinde çok sayıda veziküler görünümlü lezyonlar.

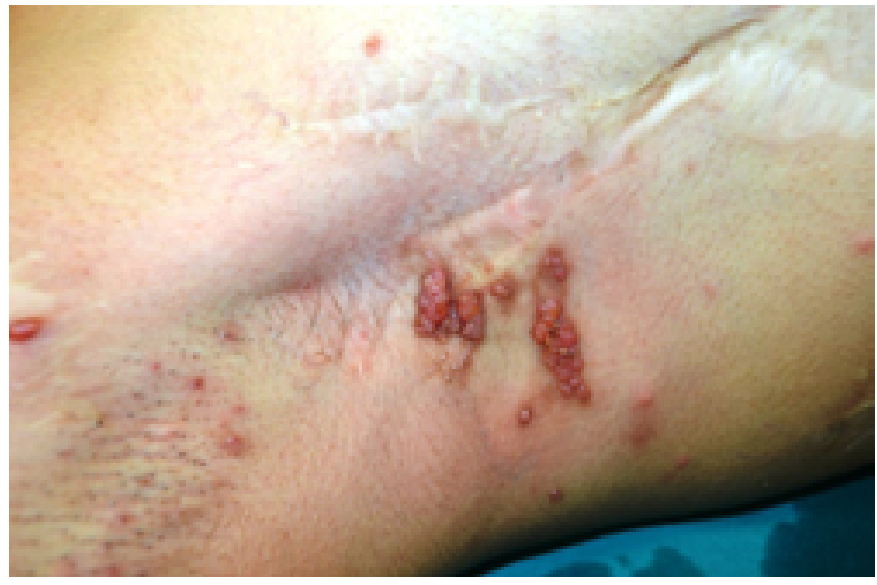

Resim 2. Hematoksilen-eozin boyamada $4 x$ büyütmede alınan görüntülerde retiküler ve papiller dermiste genişlemiş ince duvarli lenfatik damarlar

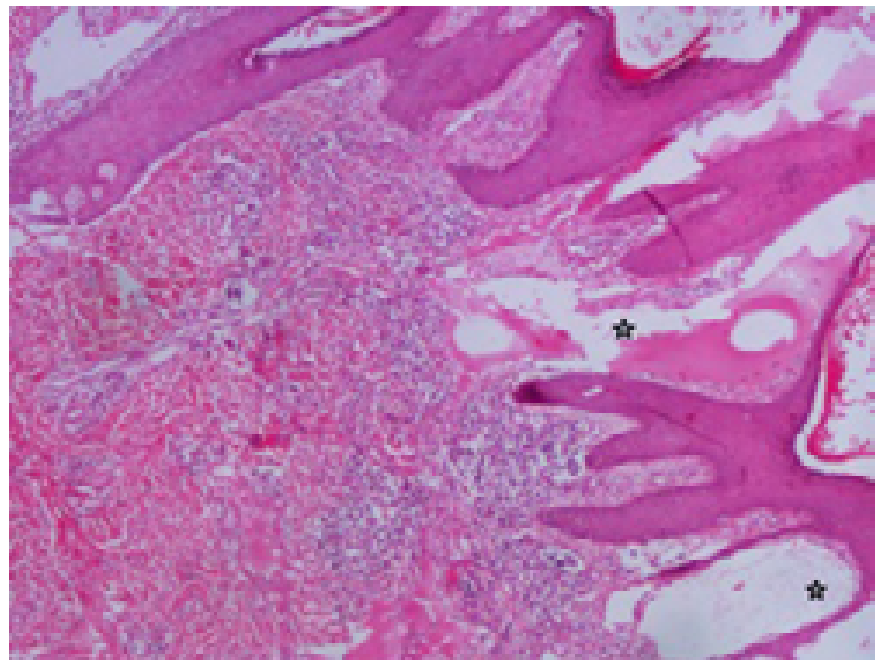

Postoperatif dönemde hastanın 1.yılında kontrollerinde geç döneme ait bir komplikasyon ve yeni lezyon saptanmadi.

\section{TARTIŞMA}

Lenfanjiyomlar hamartomatoz, konjenital malformasyonlardır.Embriyolojikolaraktüretilenlenfatik sistemin venöz sistemden gelişen tomurcuklar şeklinde oluşur. Histolojik olarak, başlıca üç tip lenfanjiyoma vardır. Bunlar lenfatik kanalların büyüklügüne bağlı olarak: kistik (makrokistik), kılcal (süper mikrokistik) ve kavernöz (mikrokistik) lenfanjiyomlardır (5).

Dermoskopi doğru öntanı koymakta çoğu zaman yardımcı olabilmektedir. Dermoskopisinde lenfanjiyoma sirkumskriptum'da laküner ve vasküler yapılar en sık karşılaşılan bulgular iken hipopiyon işareti, sarı veya beyaz lakünler ise en karakteristik bulgulardır. Lenfanjiyoma sirkumskriptumun pembemsi renk göstermesi dilate lenfatik kanallarda eritrositlerin mevcudiyeti sebebiyledir. Çoklu laküner ve vasküler yapılar lenfanjiomda olduğu gibi, hemanjiyomlarda da soliter anjiokeratomlarda da bulunur. Laküner veya vasküler yapıların kırmızı veya tromboze yapıda olması ise daha çok hemanjiom lehinedir. Soliter anjiyokeratomlarla ilişkili patern ise daha ziyade koyu renkli lakünler ve beyazımsı peçeli görünümdür $(6,7)$.

Yüzeyel lenfatik malformasyonların tanısında her ne kadar dermoskopi önemli bir rol oynasa da, tedavisinde cerrahi eksizyon ve sonrasında histolopatolojik inceleme altın standart olarak kalmaktadır (8). Cerrahi eksizyon kesin tedavi sağlayan yöntemdir ancak bazen lezyonun yeri veya büyüklüğüne bağlı olarak cerrahi morbidite yüksek olabilir, hastaya ait mortalite riskleri olabilir veya hasta uygun olmayabilir (9). Tedavi edilecek bölgelerin zorlayıcı olması ya da hastanın cerrahiye uygun olmaması durumlarında literatürde sıkça kombinasyonlar şeklinde ya da izole olarak palyatif tedavi yöntemleri de bildirilmiştir. Bunlar arasında sklerozan madde enjeksiyonu, radyofrekans ablasyonu, topikal imiqimod, elektrokoter, nonablatif lazer, karbondioksit (CO2) lazer ve Argon lazer ablasyonu yer alır (10).

Lenfanjiyoma sirkumskriptum vakalarında doğru tanı koymak ve tedavi etmek bu hastalığın rekürrens ihtimalinin bulunması ve ikincil olarak sonrasında malignite gelişebilme potansiyeli olması sebebiyle çok önemlidir.

Niitsuma ve arkadaşları çalışmalarında tamamen cerrahi olarak rezeke edilen lenfanjiyoma sirkumskriptum vakalarının \% 11 kadar rekürrens riskinin olduğunu bildirmişlerdir (11). Bizim olgumuzda da hasta daha önce aynı sebeple opere edilmiş ve ameliyat sonrası altıncı yılında rekürrens ile tarafımıza başvurmuştur. Daha önemlisi bu lezyonların radyoterapiyi takiben sekonder olarak lenfanjiosarkom ve skuamoz hücreli kanser gelișen vakalar da literatürde bildirilmiștir $(12,13)$. Shim ve arkadaşları uyluk bölgesindeki geniş bir lenfanjioma circumscriptum zemininde malign papiller vasküler anjiyoendotelyoma geliştiğini bildirmişlerdir (14).

Hazar ve arkadaşları aksilla bölgesindeki lenfanjiyoma sirkumskriptum olgusunda omuzda ağrı yarattığını bildirmişlerdir (15). Bildirdikleri olgudaki ağrı tek ve büyük bir kitlenin nörovasküler yapıları tutması veya bası yapması sebebiyle olabilir. Bizim olgumuzda ise lezyonların muhtemelen yaygın ve daha yüzeyel tutulum göstermesi nedeniyle ağrı gözlenmemiştir.

Olguda daha önce de bu tanı sebebiyle de ameliyat geçirmiş olduğu ve bazı lezyonların rekkürrens kabul edilmesi itibariyle uygun tedavi seçeneği olarak cerrahi ile tam rezeksiyon uyguladık ve hastayı takibimize aldık. Hastanın uzun dönemde rekürrens ve diğer komplikasyon olasıllkları en aza indirgenmesi hedeflenerek bütün lezyonları total olarak cerrahi eksizyon ile tedavi edildi.

Sonuç olarak bu rekürrens olmuş vaka ve literatürde bildirilmiş diğer komplike olmuş vakalar da göz önünde bulundurulduğunda; cilt renginde sert 
nodül, vezikül gibi lezyonların doğru tanısını koyarken ve tedavisini planlarken ayırıcı tanılarda lenfanjioma circumscriptumun (yüzeyel lenfatik malformasyon) da mutlaka göz önünde bulundurulmalıdır ve bir defa bu tanı konulmuş ise hastalar için tercihen en uygun tedavi olarak cerrahi rezeksiyon yapilmalı ve hastalar uzun dönem takibe alınmalıdır.

\section{KAYNAKLAR}

1. Alqahtani A, Nguyen LT, Flageole H, Shaw K,. Laberge JM. 5 years' experience with lymphangiomas in children. Journal of Pediatric Surgery 1999; 34: 11648.

2. James WD, Burger T, Elston D. Andrews' Diseases of the Skin Clinical Dermatology. 10th ed. Saunders Elsevier: United Kingdom; 2011. p.579-82

3. Kim JH, Nam TS, Kim SH. Solitary angiokeratoma developed in one area of lymphangioma circumscriptum. J Korean Med Sci. 1988; 3: 169-7

4. Terushkin V, Marmon S, Fischer M, Patel RR, Sanchez MR. Verrucous lymphangioma circumscriptum. Dermatol Online J 2012; 18: 9

5. Jha AK, Lallas A, Sonthalia S. Dermoscopy of cutaneous lymphangioma circumscriptum. Dermatol Pract Concept. 2017; 7: 37-8

6. Zaballos P, Daufı C, Puig S, Argenziano G, Moreno-Ramirez D, Cabo H, et al. Dermoscopy of solitary angiokeratomas: a morphological study. Arch Dermatol. 2007;143: 318-25.

7. Moscarella E, Zalaudek I, Buccini P, Cota C, Catricala C, Argenziano G. Dermoscopy and confocal microscopy of thrombosed hemangiomas. Arch. Dermatol 2012; 148: 410.
8. Patel GA, Schwartz RA. Cutaneous lymphangioma circumscriptum: frog spawn on the skin. Int J Dermatol. 2009; 48: 1290-5

9. Weigand S, Eivazi B, Zimmerman AP et al. Sclerother-apy of lymphangiomas of the head and neck. HeadNeck 2010; 33: 1649-55

10. Shumaker PR, Dela Rosa KM, Krakowski AC. Treatment of lymphangioma circumscriptum using fractional carbon dioxide laser ablation. Pediatr Dermatol 2013; 30: 584-6.

11. Niitsuma K, Hatoko M, Tada H, Tanaka A, Yurugi S, Iioka H. Recurrence of cutaneous lymphangioma after surgical resection: Its features and manner. European Journal of Plastic Surgery, 2005; 27: 367-70.

12. King DT, Duffy DM, Hirose FM, Gurevitch AW. Lymphangiosarcoma arising from lymphangioma circumscriptum. JAMA Dermatology 1979; 115: 969-72.

13. Wilson GR, Cox NH, McLean NR, Scott D. Squamous cell carcinoma arising within congenital lymphangioma circumscriptum. British Journal of Dermatology 1993; 129: 337-9.

14. Shim H, Hecker MS, Phelps RG. Malignant vascular papillary angioendothelioma (Dabska's tumour) arising in a lymphangioma circumscriptum: report ofa case. J Cutan Pathol 1998; 25: 513.

15. Hazar A, Aydin MS, Kocarslan A, Kürkçüoğlu İC, Göz M. Axillary Lymphangioma in Adult Patient. Selcuk Med J 2014; 30: 188-9 